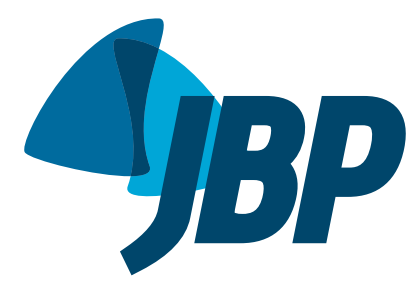

1. Universidade do Estado da Bahia UNEB - Salvador (BA) Brasil.

2. Unidade de Terapia Intensiva, Hospital Aliança, Salvador (BA) Brasil.

3. Hospital da Cidade, Salvador (BA) Brasil.

4. Curso de Fisioterapia, Programa de PósGraduação em Reabilitação e Inclusão e Biociências e Reabilitação, Centro Universitário Metodista - IPA - Porto Alegre (RS) Brasil.

5. Programa de Pós-Graduação em Medicina e Saúde, Escola Bahiana de Medicina e Saúde Pública, Salvador (BA) Brasil.

Submitted: 19 March 2015

Accepted: 19 September 2015

Study carried out at the Universidade do Estado da Bahia and at the Hospital da Cidade, Salvador (BA) Brasil.

\title{
Viability of gait speed test in hospitalized elderly patients
}

\author{
Bruno Prata Martinez ${ }^{1,2}$, Anne Karine Menezes Santos Batista ${ }^{3}$, \\ Isis Resende Ramos ${ }^{3}$, Júlio Cesar Dantas ${ }^{3}$, Isabela Barboza Gomes ${ }^{3}$, \\ Luiz Alberto Forgiarini Júnior ${ }^{4}$, Fernanda Rosa Warken Camelier ${ }^{1}$, \\ Aquiles Assunção Camelier ${ }^{1,5}$
}

\begin{abstract}
Objective: The gait speed test (GST) is a physical test that can predict falls and aid in the diagnosis of sarcopenia in the elderly. However, to our knowledge, there have been no studies evaluating its reproducibility in hospitalized elderly patients. The objective of this study was to evaluate the safety and reproducibility of the six-meter GST (6GST) in hospitalized elderly patients. Methods: This repeated measures study involved hospitalized elderly patients ( $\geq 60$ years of age) who underwent the 6GST by the fifth day of hospitalization, were able to walk without assistance, and presented no signs of dyspnea or pain that would prevent them from performing the test. The 6GST was performed three times in sequence, with a rest period between each test, in a level corridor. Gait speed was measured in meters/second. Reproducibility was assessed by comparing the means, intraclass correlation coefficients (ICCS) and Bland-Altman plots. Results: We evaluated 110 elderly patients in a total of 330 tests. All participants completed all of the tests. The comparisons between the speeds obtained during the three tests showed high ICCs and a low mean bias (Bland-Altman plots). The correlation and accuracy were greatest when the mean maximum speed was compared with that obtained in the third test $(1.26 \pm 0.44 \mathrm{~m} / \mathrm{s}$ vs. $1.22 \pm 0.44 \mathrm{~m} / \mathrm{s} ; \mathrm{ICC}=0.99 ; \mathrm{p}=0.001$; mean bias $=0.04$; and limits of agreement $=-0.27$ to 0.15 ). Conclusions: The 6GST was proven to be safe and to have good reproducibility in this sample of hospitalized elderly patients. The third measurement seems to correspond to the maximum speed, since the first two measurements underestimated the actual performance.
\end{abstract}

Keywords: Disability evaluation; Reproducibility of results; Hospitalization; Mobility limitation; Health of the elderly.

\section{INTRODUCTION}

The elderly population is considered a high-risk group for experiencing worsening health over the years; this worsening health is usually associated with decreased physical performance in activities of daily living, such as walking. ${ }^{(1)}$ However, this is a heterogeneous population, and early identification of individuals who are at high risk for future health problems is necessary. ${ }^{(2)}$ To that end, it is vital that physical tests that are reliable and that do not pose risk to the elderly be conducted, and that such tests be carried out in a hospital setting.

Some physical tests have been used in the elderly and are able to indicate an increased risk of hospitalization, worsening health status, and even an increased risk of mortality, ${ }^{(3-5)}$ as well as being one of the parameters required for the diagnosis of sarcopenia. ${ }^{(1)}$ The six-meter gait speed test (6GST) is one such assessment tool and is considered a rapid, inexpensive measure that is highly reproducible in the noninstitutionalized elderly. ${ }^{(5)}$

During hospitalization, the elderly population is at even more significant risk of a decrease in their ability to perform activities of daily living and in their cognitive function. ${ }^{(4,6)}$ Among all individuals over 60 years of age and hospitalized for external causes in Brazil, falls account for $19.3 \%$ of all hospitalizations. ${ }^{(7)}$ This finding is a cause for concern because of possible associated negative outcomes, such as nosocomial pneumonia, exacerbation of cardiorespiratory disease, and even death. ${ }^{(8,9)}$ Identifying elderly individuals at risk of falls and screening them while they are still in the hospital setting, by using tests such as the 6GST, may be a feasible approach to enable referral of such individuals for specific treatment interventions to prevent the occurrence of such outcomes.

We found no studies evaluating the safety and reproducibility of the GST in elderly Brazilians in the hospital setting. Therefore, the objective of the present study was to evaluate the safety and reproducibility of the 6GST in hospitalized elderly patients. A secondary objective was to categorize the elderly and to compare the test results among the different categories.

\section{METHODS}

This was a repeated measures study conducted between August of 2013 and January of 2014 in the ICU and Inpatient Unit (IU) of the Hospital da Cidade, located

Correspondence to:

Bruno Prata Martinez. Rua Silveira Martins, 2555, Departamento DCV I - Fisioterapia, Cabula, CEP 41150-010, Salvador, BA, Brasil.

Tel.: 5571 3117-2200. Email: brunopmartinez@hotmail.com

Financial support: None. 
in the city of Salvador, Brazil. We included patients who were 60 years of age or older, were admitted to either of those units between the first and the fifth day of their hospital stay, were not on vasoactive or inotropic drugs, could move about independently (self-report of being ambulatory without external aids) in the period prior to hospitalization, had no dyspnea or cardiorespiratory changes (systolic blood pressure $\geq 180 \mathrm{mmHg}$ or $<90 \mathrm{mmHg}$, heart rate > $100 \mathrm{bpm}$, and $\mathrm{SpO}_{2} \leq 90 \%$ ), and experienced no pain that would make the measurements impossible, as well as having physician approval to walk daily. To evaluate and increase safety during the 6GST, we considered the following test interruption criteria: precordial pain; $\mathrm{SpO}_{2} \leq 90 \%$; dizziness; pallor; nausea; sweating; palpitations; presyncope, dyspnea; accidental removal of invasive devices; falling; pain; etc. ${ }^{(10)}$

The primary variable measured was gait speed, and secondary data, such as age, gender, length of hospital stay before data collection (before the test), and the Charlson comorbidity index, ${ }^{(11)}$ were obtained from medical records. In addition, cognitive function was measured with the Mini-Mental State Examination. ${ }^{(12)}$ Patients were selected for inclusion in the study by the physical therapy staff, who checked the medical records in the electronic medical record system of the aforementioned hospital on a daily basis. The study project was approved by the Research Ethics Committee of the Escola Bahiana de Medicina e Saúde Pública (Protocol no. 567.937/14). All of the patients included in the study gave written informed consent.

After having been selected and having been instructed on how to perform the test, the individuals were taken to the corridors of each unit so that they could undergo the test. Patients were asked to walk ten meters as fast as possible without running. Time, in seconds, was measured between the second meter and the eighth meter, since the first two meters (acceleration period) and the last two meters (deceleration period) were not included in the calculation. ${ }^{(13)}$ Speed was calculated by dividing six meters by the time to walk this distance in seconds, and a speed of $\leq 0.8 \mathrm{~m} / \mathrm{s}$ was considered poor physical performance. ${ }^{(5)}$ Time in relation to distance covered was measured with a digital stopwatch (CASIO HS-3V-1; CASIO, São Paulo, Brazil), which was started when one of the legs crossed the second meter and was stopped when one of the legs crossed the eighth meter. To ensure data accuracy, markings were placed on the floor of the corridor, at zero, two, eight, and ten meters.

The total time between explanation about the test and completion of the test, including the three measurements, did not exceed 20 min, and the rest period between each gait speed measurement was $1 \mathrm{~min}$, so that patients would return to their pretest condition. If the patients did not return to their baseline condition, the rest period could be increased. However, none of the patients required that. All of the patients underwent three tests. A fourth test was not required in any of the cases, because neither a lack of patient understanding nor failures during the measurements were observed.

The sample size was calculated on the basis of two studies that reported a high correlation for the test-retest reproducibility of gait speed (intraclass correlation, 0.94-0.99). ${ }^{(14,15)}$ On this basis, we estimated, assuming a confidence interval greater than $95 \%$, a significance level of $5 \%$, and an accuracy of 10 percentage points, that the final sample size would have to be at least 73 patients.

Numerical variables were expressed as means and standard deviations, whereas categorical variables were expressed as proportions with confidence intervals. Gait speed was expressed as absolute values and was also expressed dichotomously-good physical performance vs. poor physical performance (gait speed $\leq 0.8 \mathrm{~m} / \mathrm{s}$ ). To compare the means of the fastest gait speeds, the elderly patients were categorized according to the following variables: gender; Charlson index $(\leq 4$ or $>4$ ); length of pretest hospital stay (1-3 days or 4-5 days), and collection site (ICU or IU). Subsequently, the Student's t-test for independent samples was used. Repeated-measures ANOVA was used to compare the gait speeds obtained in the three tests and in the three age groups (60-69, 70-79, and $>80$ years). In addition, for the gait speeds obtained in the three tests and the maximum speed, we calculated the intraclass correlation coefficients (ICCs) using a two-way random effects consistency model. The measurement error was determined by dividing the standard deviation of the mean difference between the measurements by the square root of two (Bland-Altman plots for absolute reliability). ${ }^{(16,17)}$ The analyses were performed with the Statistical Package for the Social Sciences, version 14.0 (SPSS Inc., Chicago, IL, USA). Values of $p<0.05$ were considered statistically significant.

\section{RESULTS}

The sample consisted of 110 elderly patients. The mean age was $71.0 \pm 8.5$ years, and the mean Charlson index was $5.4 \pm 1.8$. There was a predominance of clinical patients $(n=65 ; 59.1 \%)$. The main reason for admission was abdominal surgery ( $n=38 ; 34.5 \%$ ), followed by cardiovascular changes ( $n=22 ; 20.0 \%$ ), pneumonia ( $\mathrm{n}=15 ; 13.6 \%$ ), and skin infections ( $\mathrm{n}$ $=10 ; 9.1 \%$ ). A total of 330 6GSTs were performed, and none of the interruption criteria described in the 6GST methodology was met in any of those tests. Most measurements took place in the IU ( $n=75 ; 68.2 \%)$ and between the first and third days of hospitalization ( $n=71 ; 64.5 \%$ ), the mean hospital stay before the test being $2.7 \pm 1.6$ days (Table 1 ).

The mean maximum gait speed was $1.26 \pm 0.44$ $\mathrm{m} / \mathrm{s}$, and 15 patients $(13.6 \%)$ were classified as having poor physical performance (gait speed $\leq 0.8$ $\mathrm{m} / \mathrm{s}$ ). Comparison of gait speed among the three age categories in the present study showed that values trended downward with increasing age. Intergroup comparison showed that gait speed was fastest in 
the patients admitted for surgery, in those who were male, and in those with a Charlson index $\leq 4$ (Table 2).

In analyzing the three gait speed measurement results in each patient, we observed a progressive increase between the first and third measurements-the mean values for the first, second, and third measurements were $1.12 \pm 0.38 \mathrm{~m} / \mathrm{s}, 1.16 \pm 0.38 \mathrm{~m} / \mathrm{s}$, and $1.22 \pm 0.44$ $\mathrm{m} / \mathrm{s}$, respectively - with a significant difference between the third and first measurements (mean difference of $0.1 \mathrm{~m} / \mathrm{s} ; \mathrm{p}=0.001$; Table 3). Paired comparisons among the three measurements showed that all ICCs were high-for the comparison between the first and second measurements (ICC $=0.92 ; p=0.001$ ); for that between the first and third measurements (ICC = $0.94 ; p=0.001)$; and for that between the second and third measurements (ICC $=0.94 ; p=0.001)$. In the analysis of correlation between the maximum gait speed attained and the three measurements performed, the highest correlation was that with the third measurement (mean $=1.22 \pm 0.44 \mathrm{~m} / \mathrm{s} ;$ maximum $=1.26 \pm 0.44$ $\mathrm{m} / \mathrm{s} ; \mathrm{ICC}=0.99 ; \mathrm{p}=0.001 ;$ Figure 1 ).

The Bland-Altman plots showed low mean bias values between the measurements, as can be seen in Figure 2. In comparing all gait speed measurements, we observed that the lowest bias values $(-0.04 \mathrm{~m} / \mathrm{s})$ and the lowest limits of agreement $(-0.25$ to 0.17 $\mathrm{m} / \mathrm{s}$ ) occurred for the comparison between the third measurement and the maximum gait speed attained,

Table 1. Demographic and clinical characteristics of the study sample of 110 elderly patients. ${ }^{a}$

\begin{tabular}{|c|c|}
\hline Variable & Result \\
\hline Age, years & $71.0 \pm 8.5$ \\
\hline \multicolumn{2}{|l|}{ Cause of hospitalization } \\
\hline Abdominal surgery & $38(34.5)$ \\
\hline Cardiologic & $22(20.0)$ \\
\hline Respiratory & $15(13.6)$ \\
\hline Dermatologic & $10(9.1)$ \\
\hline Gastrointestinal & $8(7.3)$ \\
\hline Neurologic & $5(4.5)$ \\
\hline Urinary & $3(2.7)$ \\
\hline Others & $9(8.2)$ \\
\hline BMI, classification & $25.4 \pm 4.7$ \\
\hline Underweight & $3(2.7)$ \\
\hline Normal weight & $51(46.4)$ \\
\hline Overweight/obesity & $56(50.9)$ \\
\hline \multicolumn{2}{|l|}{ Gender } \\
\hline Male & $64(58.2)$ \\
\hline Female & $46(41.8)$ \\
\hline Length of pretest hospital stay, days & $2.7 \pm 1.6$ \\
\hline \multicolumn{2}{|l|}{ Type of admission } \\
\hline Clinical & $65(59.1)$ \\
\hline Surgical & $45(40.9)$ \\
\hline Charlson index & $5.4 \pm 1.8$ \\
\hline Mini-Mental State Examination & $23.7 \pm 5.0$ \\
\hline Gait speed, m/s & $1.26 \pm 0.44$ \\
\hline
\end{tabular}

which demonstrates that the third measurement was more accurate relative to the maximum speed than were the first and second measurements. Measurement variability was determined by calculating the measurement error between the tests $(0.08 \mathrm{~s})$.

\section{DISCUSSION}

The present study showed that using the 6GST in hospitalized elderly patients was safe and feasible, given that no test interruptions were required and no test-related adverse events were observed in the elderly population in the hospital setting under study. In addition, we found that, despite the high ICCs between the measurements, the third measurement was proven to be the most reliable, because its correlation with the maximum speed was the highest and because it resulted in the lowest mean bias and lowest limits of agreement. This was the first study aimed at evaluating unexpected events during the 6GST in an elderly population in the hospital setting, including some stable patients in the ICU, in Brazil.

We should also highlight the importance of using the 6GST for the diagnosis of sarcopenia, since sarcopenia is a condition that is associated with physical disability and mortality over the years in the noninstitutionalized elderly. ${ }^{(18,19)}$ Although only $20(18.1 \%)$ of the elderly patients evaluated had been hospitalized for lung problems, the 6GST, being rapid and easy to perform, can be used in patients with stable lung disease in the hospital setting(20) and even in COPD patients undergoing pulmonary rehabilitation. ${ }^{(21)}$ In the future, the 6GST may serve as a tool for the identification of respiratory morbidity (nosocomial pneumonia and exacerbation of cardiorespiratory disease) during and

Table 2. Comparison of means and standard deviations for fastest gait speed among relevant variables/categories. ${ }^{a}$

\begin{tabular}{|c|c|c|}
\hline Variable & GS, $\mathrm{m} / \mathrm{s}$ & p \\
\hline Type of admission & & 0.049 \\
\hline Clinical & $1.23 \pm 0.50$ & \\
\hline Surgical & $1.31 \pm 0.34$ & \\
\hline Gender & & 0.014 \\
\hline Female & $1.14 \pm 0.50$ & \\
\hline Male & $1.36 \pm 0.40$ & \\
\hline Charlson index & & 0.012 \\
\hline$\leq 4$ & $1.42 \pm 0.50$ & \\
\hline$>4$ & $1.20 \pm 0.40$ & \\
\hline \multicolumn{2}{|c|}{ Length of pretest hospital stay, days } & 0.863 \\
\hline $1-3$ & $1.26 \pm 0.44$ & \\
\hline $4-5$ & $1.28 \pm 0.44$ & \\
\hline Collection site & & 0.317 \\
\hline ICU & $1.20 \pm 0.43$ & \\
\hline Inpatient Unit & $1.30 \pm 0.45$ & \\
\hline Age group, years & & $<0.05$ \\
\hline $60-69$ & $1.41 \pm 0.43^{* * /+* *+*}$ & \\
\hline $70-79$ & $1.25 \pm 0.31^{* / *+*}$ & \\
\hline$>80$ & $0.86 \pm 0.44^{* / * *}$ & \\
\hline
\end{tabular}

GS: gait speed. avalues expressed as mean \pm SD. ${ }^{*} p=$ $0.002 ;{ }^{* *} \mathrm{p}=0.001 ;$ and ${ }^{* * *} \mathrm{p}=0.24$. 
Table 3. Comparison of mean differences and their respective standard deviations between gait speeds (maximum speed and speeds obtained during the three tests performed). ${ }^{\mathrm{a}}$

\begin{tabular}{|c|c|c|c|}
\hline Test & In comparison with & Difference & p \\
\hline \multirow[t]{3}{*}{ First } & Second test & $-0.04 \pm 0.02$ & 0.038 \\
\hline & Third test & $-0.100 \pm 0.018$ & 0.001 \\
\hline & Maximum speed & $-0.140 \pm 0.018$ & 0.001 \\
\hline \multirow[t]{2}{*}{ Second } & Third test & $-0.060 \pm 0.019$ & 0.001 \\
\hline & Maximum speed & $-0.100 \pm 0.019$ & 0.001 \\
\hline Third & Maximum speed & $-0.037 \pm 0.010$ & 0.001 \\
\hline
\end{tabular}

avalues expressed as mean \pm SD.
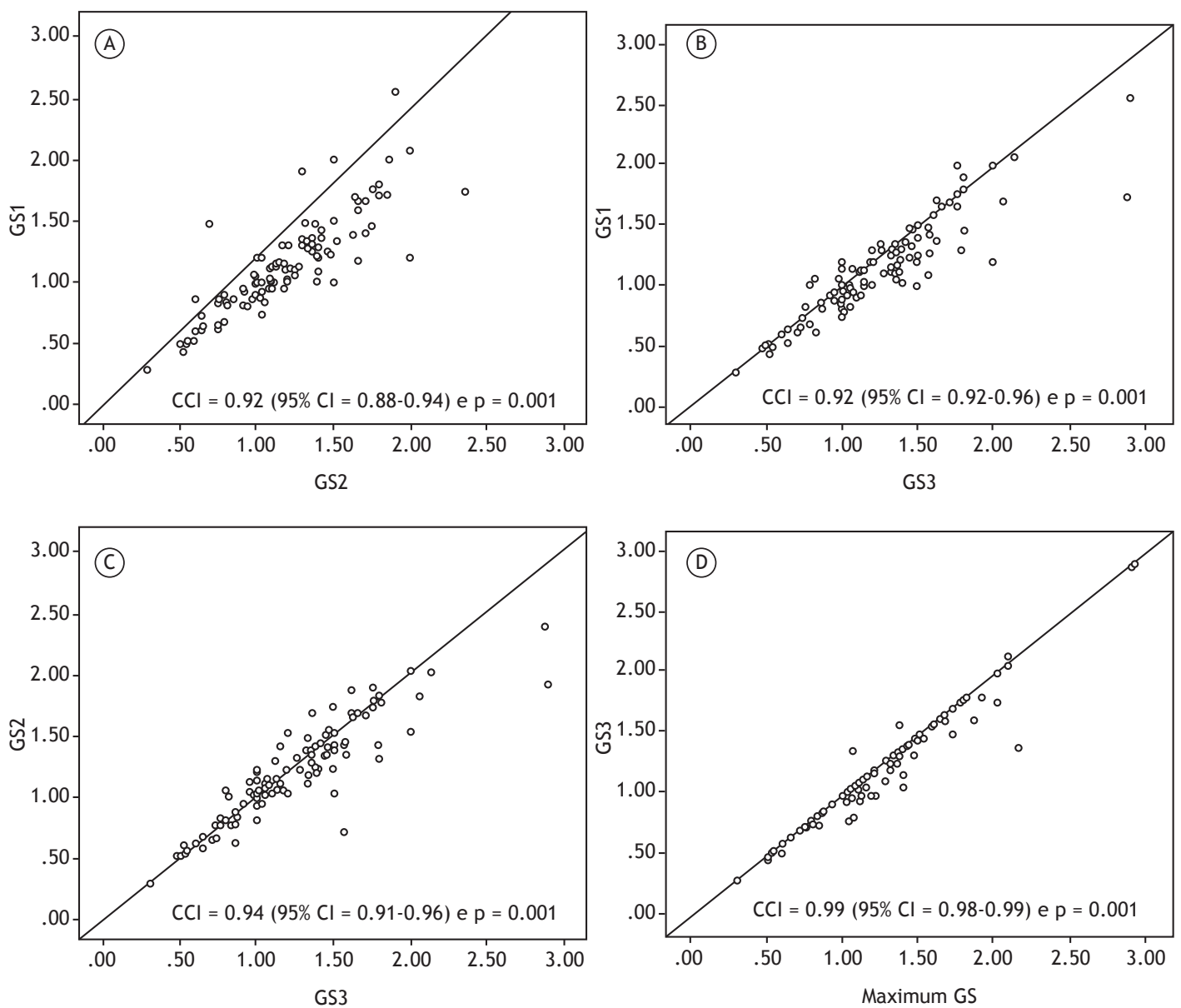

Figure 1. Intraclass correlation coefficient (ICC) analysis for the gait speed (GS) measurements-maximum speed and speeds obtained during the three tests performed (GS1, GS2, and GS3, respectively)-in the study sample $(\mathrm{N}=110)$.

after hospitalization, as well as a means of screening for sarcopenia in such a population.

An analysis of the mean gait speeds observed showed that they were within the normal ranges for the noninstitutionalized elderly (between 1.2 and $1.4 \mathrm{~m} / \mathrm{s})$. $^{(21,22)}$ One possible explanation for this finding is that our study population consisted of stable elderly patients who were not on vasoactive drugs or sedatives. In addition, the speeds observed in the present study were faster than were those reported in a recent systematic review with hospitalized elderly patients, in which gait speed ranged from 0.75 to 1.03 $\mathrm{m} / \mathrm{s}$, depending on the patient profile (acute care, subacute care, outpatient care). ${ }^{(23)}$ In contrast, in the present study, there were no differences in gait speed between the patients in the ICU and those in the IU; however, gait speed was slower in the elderly patients with higher Charlson index values. This indicates that physical performance is influenced by comorbidities and not only by the collection site.

The gait speeds obtained in the present study also indicate functional independence for activities of daily living and a lower risk of hospitalization in our study sample, since speeds were above $1.0 \mathrm{~m} / \mathrm{s}$, as reported in a previous study of the noninstitutionalized elderly. ${ }^{(24)}$ If the elderly patients already had the ability to cover the distance at a speed greater than $1.0 \mathrm{~m} / \mathrm{s}$ before hospitalization and yet were hospitalized, this might 

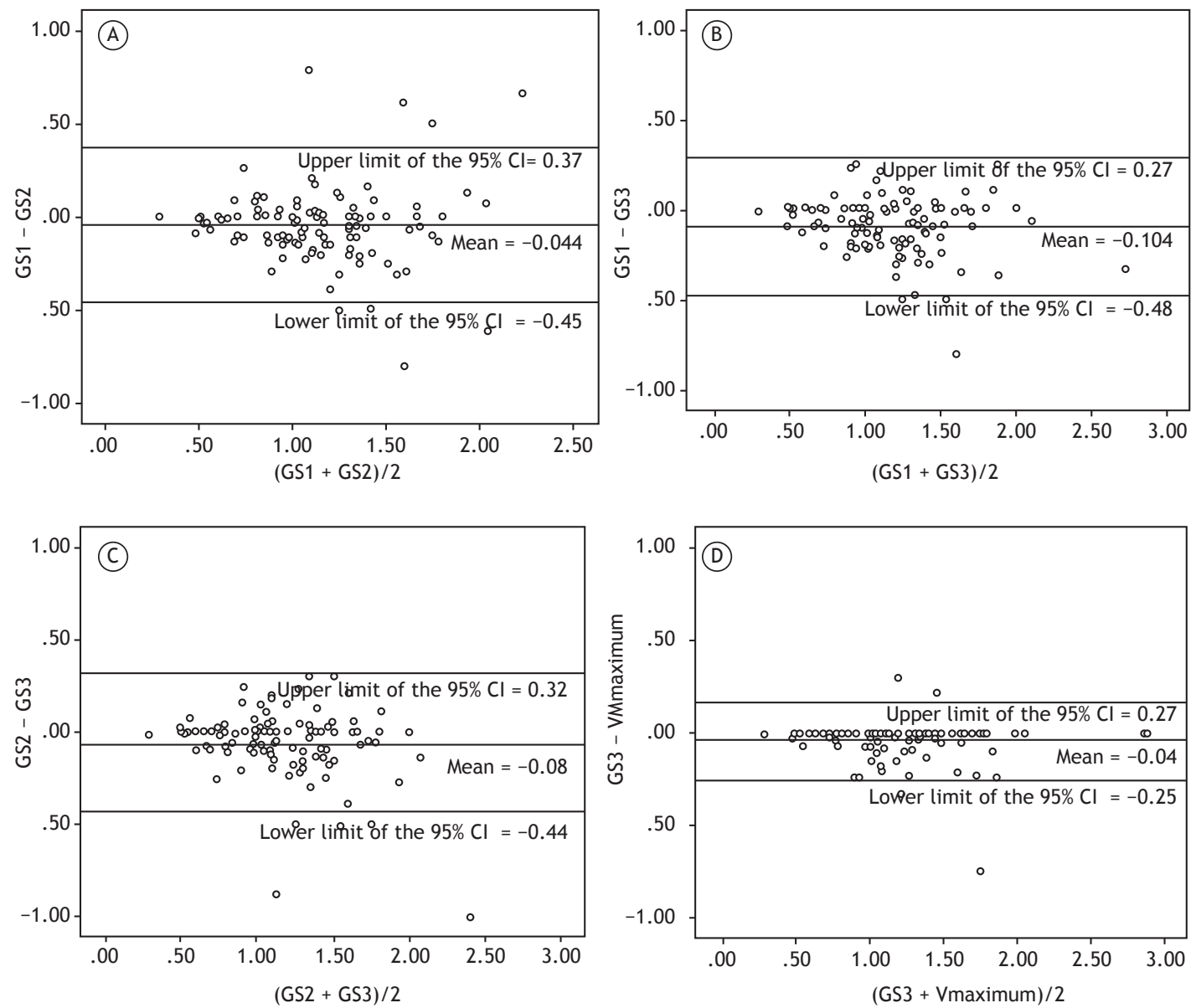

Figure 2. Bland-Altman plots for absolute reliability (means vs. differences) of the gait speed (GS) measurementsmaximum speed and speeds obtained during the three tests performed (GS1, GS2, and GS3, respectively)-in the study sample $(\mathrm{N}=110)$.

mean that this cut-off point (or even this variable) generates false-negative results, especially when the cause of hospitalization was not falls or factors related to sarcopenia, such as orthopedic problems. Nevertheless, the 6GST has been described by some authors as the "sixth vital sign",(3) because of its ability to estimate future risks of hospitalization and health decline in the elderly, particularly with regard to the ability to move from one place to another independently. ${ }^{(25)}$

Comparison of gait speed among the three age groups showed that values trended downward with increasing age, as has been shown in other studies. However, a statistically significant difference was found only between the individuals over 80 years of age and those in the two younger age groups. Between the 60-69-year age group and the 70-79-year age group, there was no significant difference, probably because of the presence of a type I error related to the sample size. Nevertheless, this difference, which was greater than $0.1 \mathrm{~m} / \mathrm{s}$, was considered clinically significant in a previous study, given that it was associated with improved health status, improved physical function, fewer hospitalization days, and lower health costs during the 1-year follow-up of elderly individuals after hospitalization. (26) The fact that gait speed was slowest in the elderly patients over 80 years of age may be linked to the effects of primary sarcopenia, caused by aging, and to those of secondary sarcopenia, caused by accompanying comorbidities or frequent physical inactivity over the years, which impairs major structures of the locomotor system. ${ }^{(1)}$

With regard to the evaluation of the reproducibility of the three 6GST measurement results for each patient and the measurement result of the best performance (maximum speed), we observed a high correlation between the measurements, a finding that is consistent with those of other studies, in which the ICC was also greater than $0.90^{(5,14,15,24)}$; however, the highest correlation found was that between the maximum speed and the third measurement. Even though there was a statistically significant difference between the first and third measurements, the mean difference was less than the standard deviation, a finding that is similar to that reported by other authors. ${ }^{(27)}$ In addition to the statistical difference, the mean difference observed $(0.1 \mathrm{~m} / \mathrm{s})$ has been considered a clinically significant change in other studies. ${ }^{(26,28)}$ The study conducted by Wilson et al. suggests that a difference greater than 
$0.05 \mathrm{~m} / \mathrm{s}$, a value that was obtained when comparing gait speed among tests, is clinically significant. ${ }^{(28)}$

In addition to having shown the highest correlation with the maximum gait speed attained, the third measurement showed the highest accuracy, as can be observed in the Bland-Altman plots. This absolute reliability analysis is relevant, given that it addresses the proximity of values, unlike ICC analysis, which deals with the linear association between measurements. Although the accuracy and mean bias were less than $0.05 \mathrm{~m} / \mathrm{s}$, a value considered clinically significant in a previous study, ${ }^{(27)}$ the limits of agreement $(-0.25$ to $0.17 \mathrm{~m} / \mathrm{s}$ ) were greater than $0.1 \mathrm{~m} / \mathrm{s}$, a value considered predictive of well-being. ${ }^{(26)}$ The measurement variability of 0.08 observed in the present study was also greater than the 0.05 value reported in the Wilson et al. study. $w^{(28)}$ One possible explanation for this is the effect of learning and motivation to perform the test, since the third measurement showed smaller differences between means, a higher ICC, and a lower mean bias than did the first two measurements.

Poor physical performance, which is predictive of adverse outcomes, was observed for only a small proportion of the total sample ( $n=15 ; 13.6 \%$ ), and that might have accounted for the absence of complications, such as falls and cardiorespiratory instability, during the test. However, despite being stable, all of the elderly patients showed some level of disease severity, since the mean Charlson index was $>5$ and some patients were in the ICU.

In addition to being easily reproducible, because of its short duration and its minimal requirement of space, the 6GST is found to be safe and may be able to identify patients at risk for poor outcomes, as well as being useful in predicting the prognosis of such patients. In the future, the 6GST should be routinely used in hospital units, including ICUs, in elderly patients who are stable and fit to undergo the test, since there is an association between gait speeds and referral to units that can treat clinical and functional complications. ${ }^{(29,30)}$ In addition, values obtained at hospital discharge may have some association with prognosis over time.

Our study has some limitations, such as the fact that gait speed was not compared with any measure of physical performance considered to be the gold standard in the hospital setting. However, this can be justified by the lack of physical tests that can be used in this setting. Another test that could be used is the six-minute walk test. However, the purpose of the six-minute walk test is different from that of GSTs, since the former measures individual aerobic capacity and the latter measure mobility. Another limitation is that the study was conducted at a single center. In addition, gait speed was measured in individuals who were ambulatory without external aids, which limits the external validity of the results to such patients. Future studies, evaluating patients at discharge and thereafter, are warranted in order to allow the analysis of medium- and long-term outcomes.

The 6GST was proven to be a safe measure of physical performance and to have good reproducibility in our sample of elderly patients evaluated in the hospital setting. Of the three gait speed measurements performed for each elderly patient, the third one seems to correspond to the maximum speed, since the first two measurements underestimated the actual physical performance in most cases.

\section{REFERENCES}

1. Cruz-Jentoft AJ, Baeyens JP, Bauer JM, Boirie Y, Cederholm T, Landi $F$, et al. Sarcopenia: European consensus on definition and diagnosis: Report of the European Working Group on Sarcopenia in Older People. Age Ageing. 2010;39(4):412-23. http://dx.doi.org/10.1093/ ageing/afq034

2. Cesari M, Kritchevsky SB, Penninx BW, Nicklas BJ, Simonsick EM, Newman AB, et al. Prognostic value of usual gait speed in wellfunctioning older people--results from the Health, Aging and Body Composition Study. J Am Geriatr Soc. 2005;53(10):1675-80. http:// dx.doi.org/10.1111/j.1532-5415.2005.53501.x

3. Fritz S, Lusardi M. White paper: "walking speed: the sixth vital sign". J Geriatr Phys Ther. 2009;32(2):46-9. http://dx.doi. org/10.1519/00139143-200932020-00002

4. Cawthon PM, Marshall LM, Michael Y, Dam TT, Ensrud KE, BarrettConnor $\mathrm{E}$, et al. Frailty in older men: prevalence, progression, and relationship with mortality. J Am Soc Geriatr. 2007;55(8):1216-23. http://dx.doi.org/10.1111/j.1532-5415.2007.01259.x

5. Abellan van Kan G, Rolland Y, Andrieu S, Bauer J, Beauchet O, Bonnefoy $M$, et al. Gait speed at usual pace as a predictor of adverse outcomes in community-dwelling older people an International Academy on Nutrition and Aging (IANA) Task Force. J Nutr Health Aging. 2009;13(10):881-9. http://dx.doi.org/10.1007/s12603-0090246-z

6. Fried LP, Tangen CM, Walston J, Newman AB, Hirsch C, Gottdiener $J$, et al. Fraity in older adults: evidence for a phenotype. J Gerontol A Sci Med Sci. 2001;56(3):M146-56.

7. Departamento de Informática do SUS - DATASUS [homepage on the Internet]. Brasília: Ministério da Saúde [cited 2014 May 29]. Available from: http://www2.datasus.gov.br/
8. Iglesias CP. Manca A, Torgerson DJ. The health-related quality of life and cost implications of falls in elderly women. Osteoporos Int. 2009;20(6):869-78. http://dx.doi.org/10.1007/s00198-008-0753-5

9. Fhon JR, Rosset I, Freitas CP, Silva AO, Santos JL, Rodrigues RA. Prevalence of falls among frail elderly adults. Rev Saude Publica. $\quad$ 2013;47(2):266-73. http://dx.doi.org/10.1590/S00348910.2013047003468

10. Stiller K. Safety issues that should be considered when mobilizing critically ill patients. Crit Care Clin. 2007;23(1):35-53. http://dx.doi. org/10.1016/j.ccc.2006.11.005

11. Charlson ME, Pompei $P$, Ales $K L$, MacKenzie CR. A new method of classifying prognostic comorbidity in longitudinal studies: development and validation. J Chronic Dis. 1987;40(5):373-83. http:// dx.doi.org/10.1016/0021-9681(87)90171-8

12. Lourenço RA, Veras RP. Mini-mental State Examination: psychometric characteristics in elderly outpatients [Article in Portuguese]. Rev Saude Publica. 2006;40(4):712-9. http://dx.doi. org/10.1590/S0034-89102006000500023

13. Ostir GV, Volpato S, Fried LP, Chaves P, Guralnik JM; Women's Health and Aging Study. Reliability and sensitivity to change assessed for a summary measure of lower body function: results from the Women's Health and Aging Study. J Clin Epidemiol. 2002;55(9):91621. http://dx.doi.org/10.1016/S0895-4356(02)00436-5

14. Kon SS, Patel MS, Canavan JL, Clark AL, Jones SE, Nolan CM, et al. Reliability and validity of 4-metre gait speed in COPD. Eur Resp J. 2013;42(3):333-40. http://dx.doi.org/10.1183/09031936.00162712

15. Flansbjer U, Holmbäck AM, Downham D, Patten C, Lexell J. Reliability of gait performance tests in men and women with hemiparesis after stroke. J Reahabil Med. 2005;37(2):75-82. http:// 
dx.doi.org/10.1080/16501970410017215

16. Altman DG, Bland JM. Measurement in medicine: the analysis of method comparison studies. Statistician. 1983;32:307-17. http:// dx.doi.org/10.2307/2987937

17. LexellJE, DownhamDY. Howtoassess the reliability ofmeasurements in rehabilitation. Am J Phys Med Rehabil. 2005;84(9):719-23. http:// dx.doi.org/10.1097/01.phm.0000176452.17771.20

18. da Silva Alexandre T, de Oliveira Duarte YA, Ferreira Santos JL, Wong R, Lebrão ML. Sarcopenia according to the european working group on sarcopenia in older people (EWGSOP) versus Dynapenia as a risk factor for disability in the elderly. J Nutr Health Aging. 2014;18(5):54753. http://dx.doi.org/10.1007/s12603-014-0465-9

19. Martinez BP, Batista AK, Gomes IB, Olivieri FM, Camelier FW Camelier AA. Frequence of sarcopenia and associated factors among hospitalized elderly patients. BMC Musculoskelet Disord. 2015;16:108. http://dx.doi.org/10.1186/s12891-015-0570-x

20. Jones SE, Maddocks M, Kon SS, Canavan JL, Nolan CM, Clark AL, et al. Sarcopenia in COPD: prevalence, clinical correlates and response to pulmonary rehabilitation. Thorax. 2015;70(3):213-8. http://dx.doi. org/10.1136/thoraxjnl-2014-206440

21. Lernier-Frankiel M, Vargas S, Brown M, Krusell L, Schoneberger W. Functional community ambulation: what are your criteria? Clin Manag Phys Ther. 1986;6:12-5.

22. Bohannon RW, Williams Andrews AW. Normal walking speed: descriptive meta-analysis. Physiotherapy. 2011;97(3):182-9. http:// dx.doi.org/10.1016/j.physio.2010.12.004

23. Peel NM, Kuys SS, Klein K. Gait speed as a measure in geriatric assessment in clinical settings: a systematic review. J Gerontol A
Biol Sci Med Sci. 2013;68(1):39-46. http://dx.doi.org/10.1093/gerona/ gls174

24. Studenski SA, Perera S, Wallace D, Chandler JM, Duncan PW Rooney $\mathrm{E}$, et al. Physical performance measures in the clinical setting. J Am Geriatr Soc. 2003;51(3):314-22. http://dx.doi. org/10.1046/j.1532-5415.2003.51104.x

25. Rosa TE, Benício MH, Latorre Mdo R, Ramos LR. Determinant factors of functional status among the elderly [Article in Portuguese]. Rev Saude Publica. 2003;37(1):40-8

26. Purser JL, Weinberger M, Cohen HJ, Pieper CF, Morey MC, Li T, et al. Walking speed predicts health status and hospital costs for frail elderly male veterans. J Rehabil Res Dev. 2005;42(4):535-46. http:// dx.doi.org/10.1682/JRRD.2004.07.0087

27. Wilson CM, Kostsuca SR, Boura JA. Utilization of a 5-Meter Walk Test in Evaluating Self-selected Gait Speed during Preoperative Screening of Patients Scheduled for Cardiac Surgery. Cardiopulm Phys Ther J. 2013;24(3):36-43.

28. Perera S, Mody SH, Woodman RC, Studenski SA. Meaningful change and responsiveness in common physical performance measures in older adults. J Am Geriatr Soc. 2006;54(5):743-9. http:// dx.doi.org/10.1111/j.1532-5415.2006.00701.x

29. Hardy SE, Perera S, Roumani YF, Chandler JM, Studenski SA Improvement in usual gait speed predicts better survival in older adults. J Am Geriatr Soc. 2007;55(11):1727-34. http://dx.doi. org/10.1111/j.1532-5415.2007.01413.x

30. Rabadi $\mathrm{MH}$, Blau A. Admission ambulation velocity predicts length of stay and discharge disposition following stroke in an acute rehabilitation hospital. Neurorehabil Neural Repair. 2005;19(1):20-6. http://dx.doi.org/10.1177/1545968304272762 